\title{
Deformation and Failure Properties of High-Ni Lithium-Ion Battery under Axial Loads
}

\author{
Genwei Wang ${ }^{1,2, *}$, Shu Zhang ${ }^{2,3}$, Meng $\mathrm{Li}^{2,3}$, Juanjuan $\mathrm{Wu}^{2,3}$, Bin Wang ${ }^{4, *}$ (D) and Hui Song ${ }^{2,3}$ \\ 1 College of Aeronautics and Astronautics, Taiyuan University of Technology, Jinzhong 030600, China \\ 2 Shanxi Key Laboratory of Material Strength and Structure Impact, Taiyuan 030024, China; \\ zhangshu0037@163.com (S.Z.); leemeng2021@163.com (M.L.); july0033@163.com (J.W.); \\ songhui@tyut.edu.cn (H.S.) \\ 3 College of Mechanical and Vehicle Engineering, Taiyuan University of Technology, Taiyuan 030024, China \\ 4 Department of Mechanical and Aerospace Engineering, Brunel University London, London UB8 3PH, UK \\ * Correspondence: gwang@tyut.edu.cn (G.W.); bin.wang@brunel.ac.uk (B.W.)
}

Citation: Wang, G.; Zhang, S.;

Li, M.; Wu, J.; Wang, B.; Song, H.

Deformation and Failure Properties of High-Ni Lithium-Ion Battery under Axial Loads. Materials 2021, 14, 7844. https://doi.org/10.3390/ma14247844

Academic Editors: Satyam Panchal, Cai Shen and Arash Soleiman-Fallah

Received: 12 November 2021 Accepted: 15 December 2021 Published: 18 December 2021

Publisher's Note: MDPI stays neutral with regard to jurisdictional claims in published maps and institutional affiliations.

Copyright: (c) 2021 by the authors. Licensee MDPI, Basel, Switzerland. This article is an open access article distributed under the terms and conditions of the Creative Commons Attribution (CC BY) license (https:// creativecommons.org/licenses/by/ $4.0 /)$.

\begin{abstract}
To explore the failure modes of high-Ni batteries under different axial loads, quasi-static compression and dynamic impact tests were carried out. The characteristics of voltage, load, and temperature of a battery cell with different states of charge (SOCs) were investigated in quasi-static tests. The mechanical response and safety performance of lithium-ion batteries subjected to axial shock wave impact load were also investigated by using a split Hopkinson pressure bar (SHPB) system. Different failure modes of the battery were identified. Under quasi-static axial compression, the intensity of thermal runaway becomes more severe with the increase in SOC and loading speed, and the time for lithium-ion batteries to reach complete failure decreases with the increase in SOC. In comparison, under dynamic SHPB experiments, an internal short circuit occurred after impact, but no violent thermal runaway was observed.
\end{abstract}

Keywords: cylindrical lithium-ion battery; axial load; failure mechanism; thermal runaway

\section{Introduction}

With the aim to reduce $\mathrm{CO}_{2}$ release, $\mathrm{EV}$ technology and $\mathrm{EV}$ market demand have both experienced vigorous developments to replace vehicles driven by internal combustion engines (ICEs) [1]. Among the several mainstream commercial batteries available on the market, lithium-ion batteries are favored by the EV industry due to their high energy density, good cycling performance, and lack of memory effect. However, safety accidents of lithium-ion batteries characterized by thermal runaway occur from time to time, undermining the public's confidence in electric vehicles [2,3]. Lithium-ion batteries with lithium iron phosphate and ternary materials (mainly NCA and NCM as cathode materials) are extensively used in EVs [4] for high energy density. The probability of thermal runaway poses a serious threat of fire and explosion [5,6]. In many EV accidents, fires originate from the destruction of battery cells' structural integrity, often caused by mechanical damage during vehicle operations, leading to violent thermal runaway [7].

In EVs, cylindrical battery cells are usually placed vertically and stacked horizontally to form modules. This unique arrangement leads to complex loading conditions. Xia et al. [8] analyzed battery fire accidents caused by foreign body collision at the bottom of EVs and established a model to study battery deformation and possible failure modes under axial loading of indenters with different shapes. Zhu et al. [9] studied axial compression experimentally and found that the force-displacement curve of the battery shows a four-stage character before short circuiting, i.e., slow rise, fast rise, slight decline, and fast rise. Finite element simulations were carried out to reveal the deformation processes, which were verified by computerized tomography (CT) scans. The researchers found that most deformation occurred at the top of the cell, with little at the bottom. 
Compared with axial compression, more studies on the radial compression of cylindrical batteries are available, including the influence of $\mathrm{SOC}, \mathrm{SOH}$, loading form, and rate on battery performance. Xu et al. [10-12] studied the influence of SOC under quasi-static loading conditions and established a battery model showing that mechanical properties of batteries are highly dependent on $\mathrm{SOC}$ and weakened with a decrease in $\mathrm{SOH}$. In addition, compression [13,14], three-point bending [15,16], and indentation [17] have been studied in large quantities as common loading conditions. Hao et al. [18] studied the failure process of a cylindrical lithium-ion battery under three-point bending using acoustic emission technology. Gao et al. $[19,20]$ investigated the influence of overcharge, short-term cycle, and low-temperature charge on the mechanical integrity of battery cells subject to lateral compression. It was found that moderate overcharge has little influence on thermal runaway of the battery, while low-temperature charge reduces the crushing stress of the battery cell. Panchal et al. [21,22] studied the degradation and thermal characteristics of $\mathrm{LiFePO}_{4}$ batteries through experiments and established a model to analyze the attenuation of lithium iron phosphate batteries. Duan et al. [23] modeled and analyzed the heat dissipation problem of liquid cooling lithium-ion batteries. Kisters et al. [24] also conducted dynamic impact tests of pouch cells and elliptic cells and found that the failure load of elliptic cells increases with the loading speed, while the failure load of pouch cells decreases. The effect of electrolyte on the performance of an elliptic cell was also studied. It was found that the indentation of a dry cell is deeper with a higher impact velocity, but the slope of the load-displacement curve does not change much. In contrast, the depth of failure indentation in wet battery cells decreases, and the slope of the load-displacement curve increases with the increase in loading speed.

As already known, an increase in Ni content reduces the thermal safety of a battery, but few studies are available on the safety of high-nickel batteries under axial impact [25]. This paper presents an experimental study on the mechanical and safety properties of high-nickel batteries under both static and dynamic axial load experiments. CT scan was used to detect the internal damage of the batteries after the tests. This study is a step toward understanding the safety behavior of lithium-ion batteries under different axial loads.

\section{Experimental Section}

\subsection{Information of the Cell}

A commercial model of cylindrical high-nickel lithium-ion cells with $\mathrm{LiNi}_{0.8} \mathrm{Co}_{0.1} \mathrm{Mn}_{0.1} \mathrm{O}_{2}$ as cathode material was used in this study. The battery is $65 \mathrm{~mm}$ in length and $18 \mathrm{~mm}$ in diameter with a nominal energy capacity of $3050 \mathrm{mAh}$ and a nominal voltage of $3.6 \mathrm{~V}$. The jellyroll is shown in Figure 1, which includes an anode, a cathode, a collector, and a separator comprising the internal structure of the cell.

\subsection{Experimental Methods}

Before the tests, all batteries were charged to a fixed SOC. During charging and discharging, the C-rate is a commonly used term to express the charge and discharge rates. The C-rate is equal to the charge or discharge current divided by the rated capacity. At this stage, all batteries were charged in the CC-CV mode [26]. In this process, batteries were first charged at $0.2 \mathrm{C}$ to a rated voltage of $4.2 \mathrm{~V}$, charged at a constant voltage of $4.2 \mathrm{~V}$ until the current was less than $0.02 \mathrm{C}$, then discharged at a constant current of $0.2 \mathrm{C}$ to the cut-off voltage. After standing, they were charged again at a constant rate of $0.2 \mathrm{C}$ to different SOCs.

A quasi-static test was then carried out using a Gotech screw-driven testing machine (Gotech Testing Machines Inc., Taiwan, China) with a loading capacity of up to $30 \mathrm{kN}$, as shown in Figure 2a. During the test, voltage changes of the battery were recorded by a digital oscilloscope. The battery was connected with a digital oscilloscope to monitor the voltage change, then the battery was placed on the testing machine and loaded at a specified loading rate. Temperature changes of the battery were recorded by an infrared thermal imager (Yoseen X640A600MF25, Wuhan Yoseen Infrared Co., Ltd., Wuhan, China). 


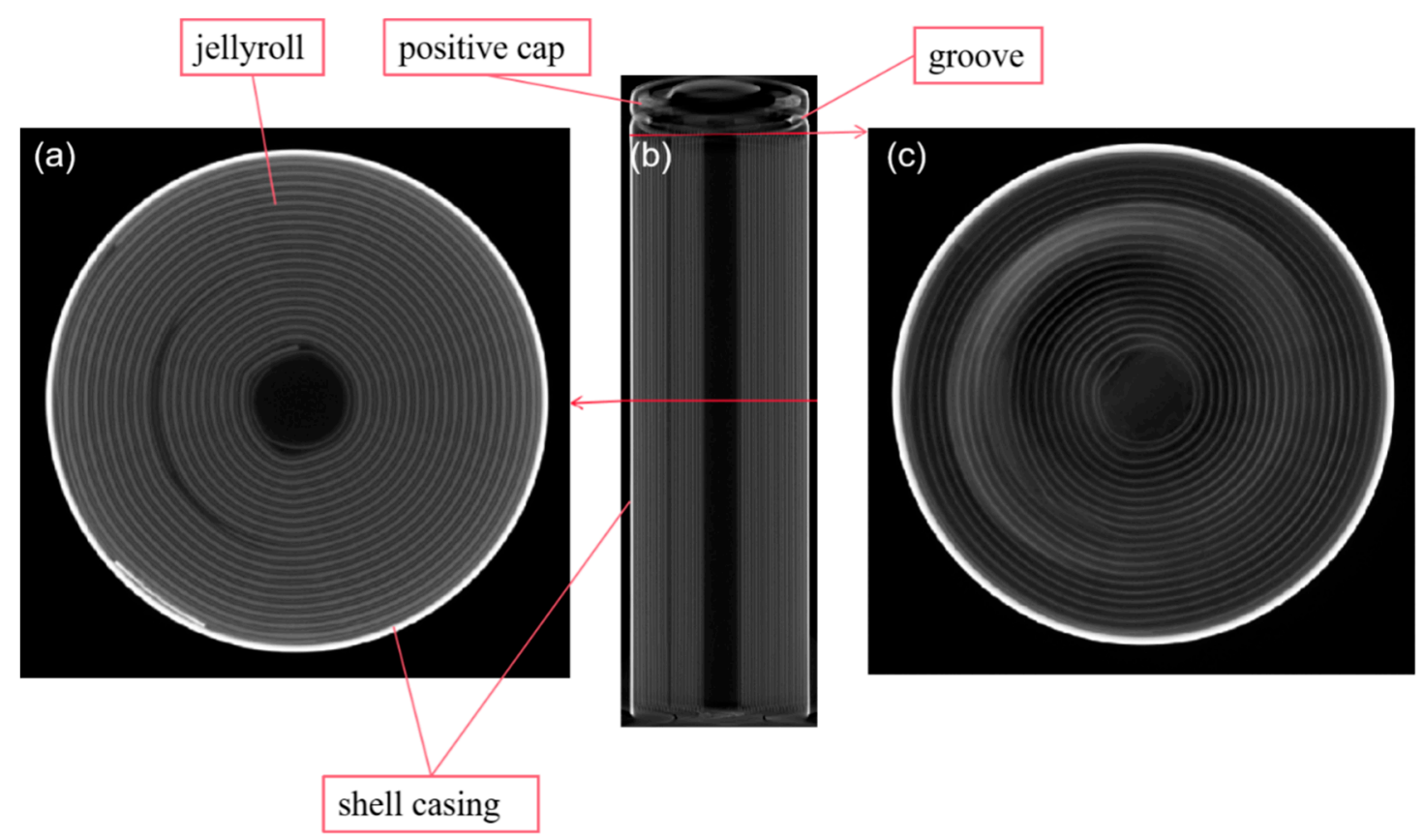

Figure 1. CT inspection of the battery studied: (a) cross-section of the midsection; (b) side view; (c) cross-section of the top section.
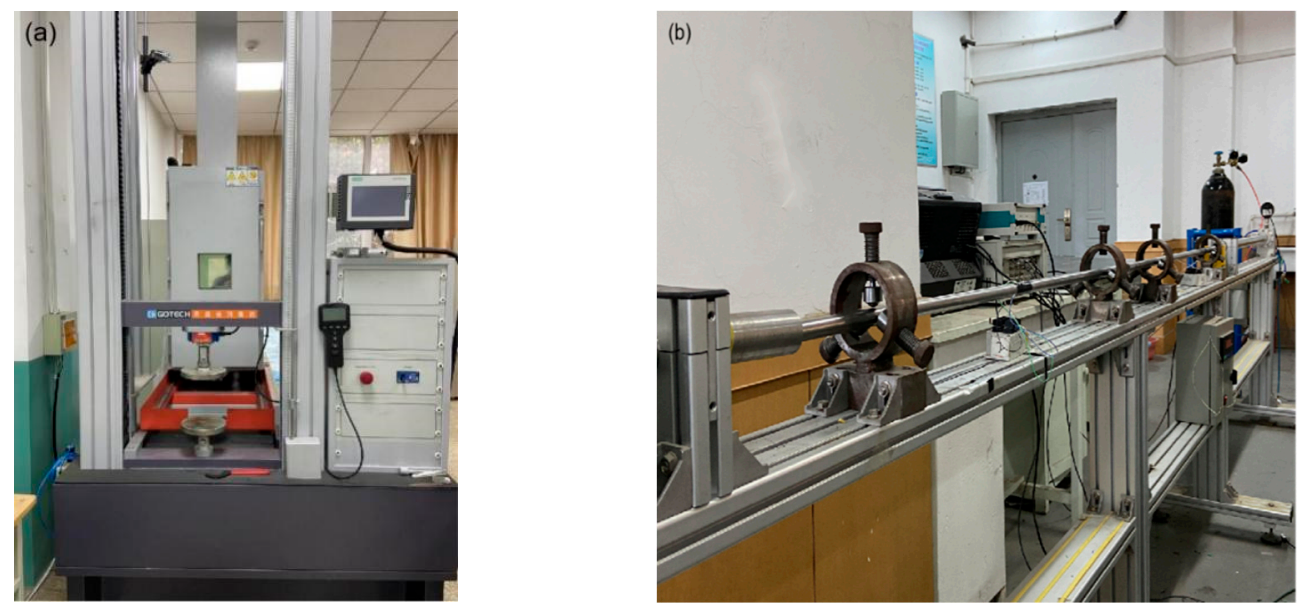

Figure 2. (a) Gotech testing machine; (b) SHPB system set-up.

In the dynamic axial impact test, a $19 \mathrm{~mm}$ diameter SHPB system was used, and a high-speed camera (I-Speed 716, iX Cameras Ltd., Rochford, England) was used to record the deformation process with a sampling rate of $75 \mathrm{kHz}$, as illustrated in Figure $2 \mathrm{~b}$. The battery was placed axially between the incident bar and a fixed plate. A laser velocimeter was used to measure the speed of the striking bullet, which hit the far end of the incident bar to apply a compressive stress wave on the battery. Each test was repeated three times, and the mean value was used to reduce experimental uncertainty.

\section{Results}

\subsection{Quasi-Static Experiment}

Batteries with $0 \%, 20 \%, 40 \%, 60 \%$, and $80 \%$ SOCs were tested. The crosshead displacement loading was set at a constant speed of $2 \mathrm{~mm} / \mathrm{min}$. In order to determine the influence of loading speed on thermal runaway, additional compression tests at $8 \mathrm{~mm} / \mathrm{min}$ were also carried out on cells with $40 \%$ and $60 \%$ SOCs. 
Figure 3 shows the load-deformation curves of lithium-ion batteries with different SOCs. With increasing deformation, loads on the batteries with different SOCs show a virtually identical upward trend in the early stage. When deformation exceeded $2 \mathrm{~mm}$, batteries with $40 \%$ SOC and above soon reached the peak load and failed, indicated by a sudden loss (dive) in voltage. Batteries with $0 \%$ and $20 \%$ SOCs deformed further with a plateau load with further deformation after reaching the peak load.

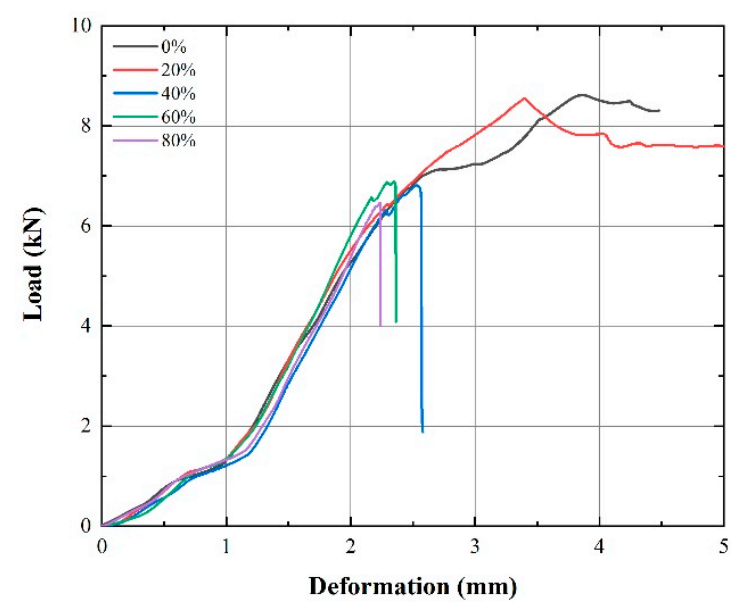

Figure 3. Load-deformation curves of batteries with $0 \%, 20 \%, 40 \%, 60 \%$, and $80 \%$ SOCs under axial compression at $2 \mathrm{~mm} / \mathrm{min}$.

Temperature and voltage changes in the batteries were collected with respect to the deformation. Figure 4a-e shows the voltage, load, and temperature of batteries with $0 \%, 20 \%, 40 \%, 60 \%$, and $80 \%$ SOCs. It can be seen that all batteries with a higher SOC experienced thermal runaway.
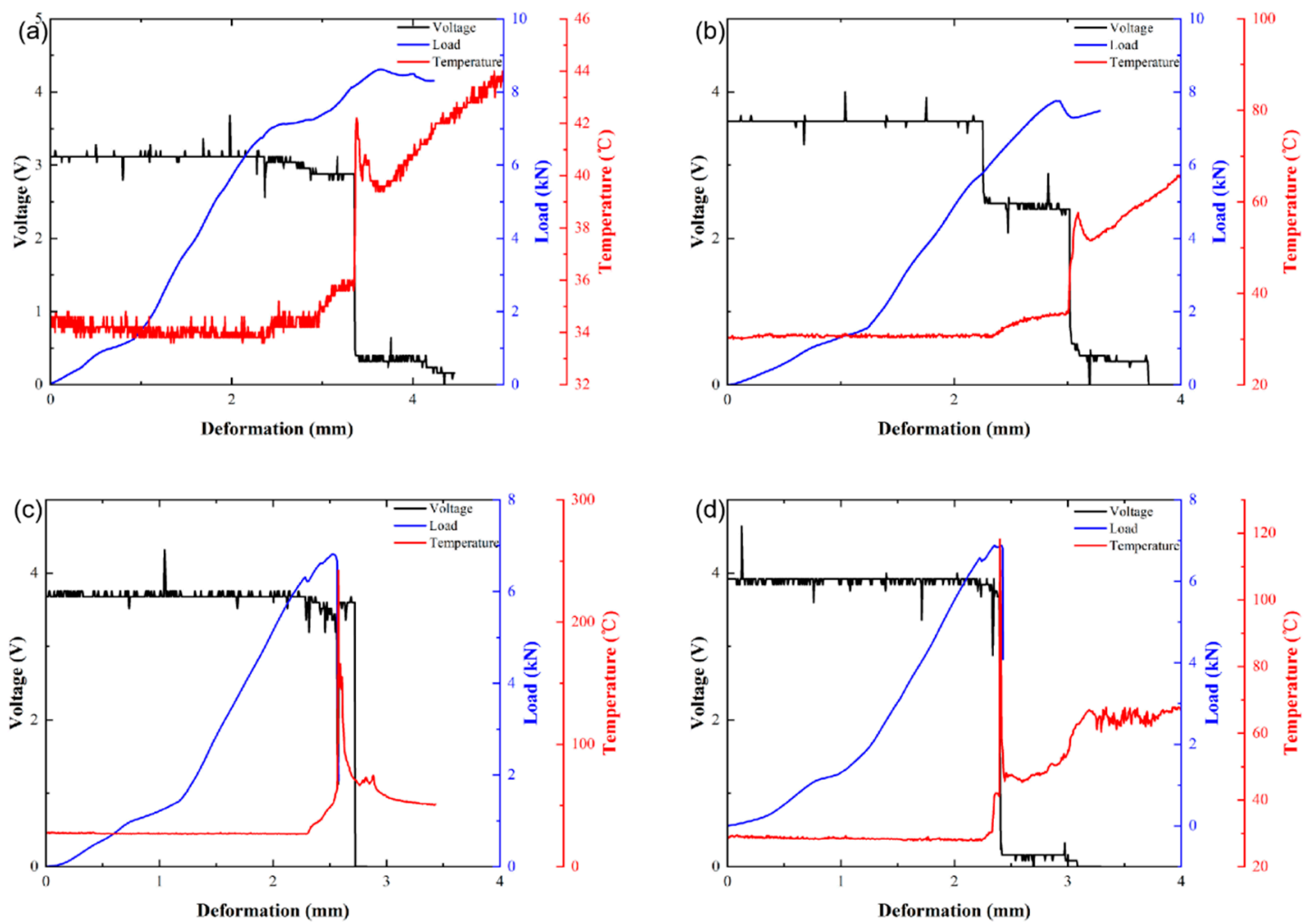

Figure 4. Cont. 


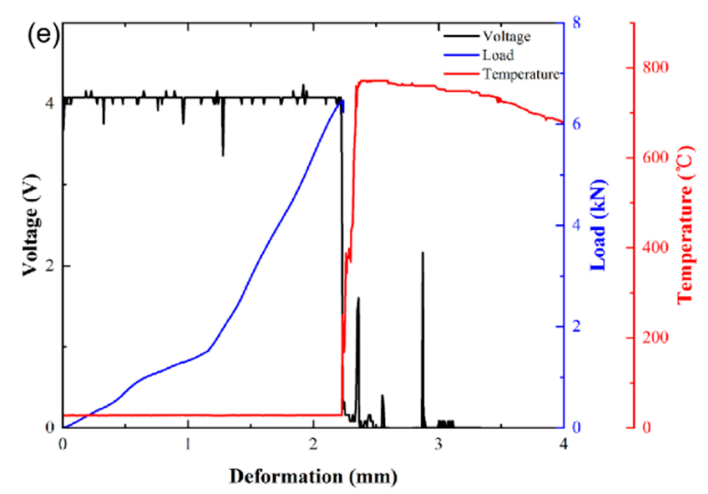

Figure 4. Voltage, load, and temperature-deformation curves of batteries with different SOCs: (a) $0 \%$; (b) 20\%; (c) 40\%; (d) $60 \%$; (e) $80 \%$.

The load-deformation curve of a $0 \%$ SOC battery is further analyzed in Figure 5 . The compression process can be divided into four stages. In Stage I, the groove of the positive cap at the battery top is flattened with the cap just in contact with the jellyroll. In Stage II, the jellyroll is pushed and compressed by the positive cap and shows increasing resistance. In Stage III, the jellyroll starts to bend and buckle in the lateral direction, resulting in the initiation of internal short circuiting. In Stage IV, the local area of the jellyroll deforms excessively, and internal short circuiting becomes more severe. This is similar to the experimental results of Zhu et al. [9], but the voltage change is significantly different, which is caused by the difference in the inner structures of the battery and the properties of different electrode materials.

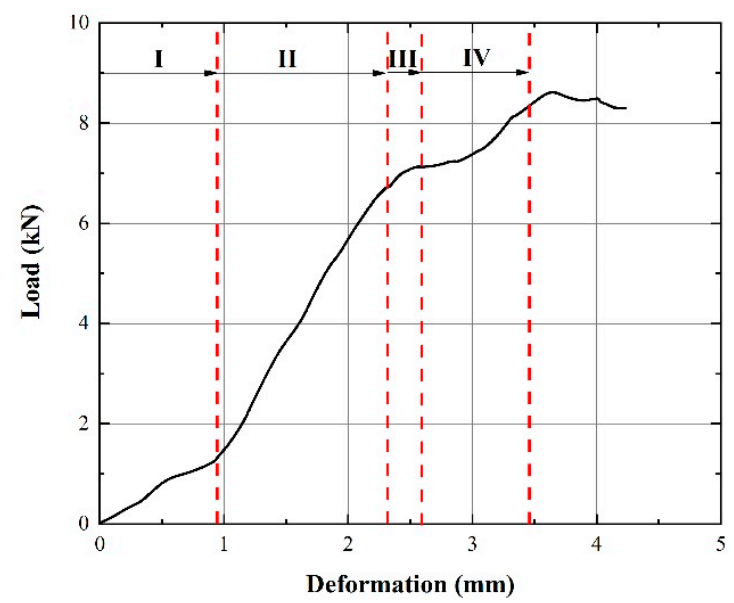

Figure 5. Stages of the load-deformation curve of a battery with $0 \%$ SOC under axial compression.

As shown in Figure $4 \mathrm{c}, \mathrm{d}$, the temperature of batteries with $40 \%$ and $60 \%$ SOCs begins to rise, and the voltage drop starts in Stage III. At the end of Stage III, the temperature rises sharply, and the battery reaches the failure state. In comparison, batteries with $80 \%$ SOC show a sudden temperature rise and a complete voltage drop at the end of Stage II (Figure 4e), and the maximum temperature reaches nearly $800{ }^{\circ} \mathrm{C}$. It can clearly be seen that the severity of thermal runaway increases with the SOC.

CT inspections at the end of Stage II of the longitudinal section in Figure 6a show that the jellyroll was squeezed by the positive cap and began to deform. With part of the jellyroll buckled, gaps appeared in the negative current collector, as shown in Figure $6 \mathrm{~b}$, and cross-layer deformation occurred in the jellyroll near the top of the battery, yielding in direct contact with the positive and negative poles. Figure $6 \mathrm{c}-\mathrm{e}$ shows the Joule heat generated around the contact area with the increased potential of thermal runaway. The short-circuit current in the damaged area increases with the battery's SOC, resulting in an increase in Joule heat and a higher temperature. Therefore, batteries with excessively 
high SOCs experience severe thermal runaway, such as those of batteries with $80 \%$ SOC, as shown in Figure 6e. In Figure 6f, it can be seen that the battery erupted into flames near the positive electrode.

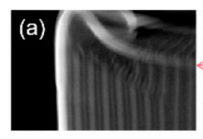

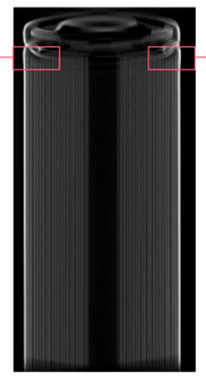
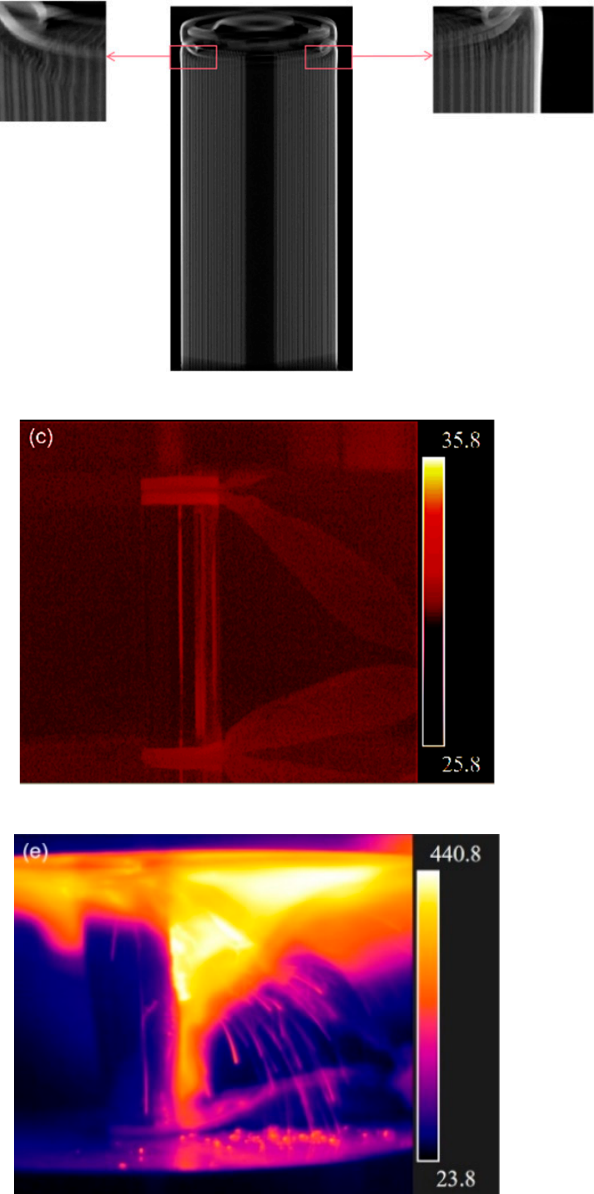
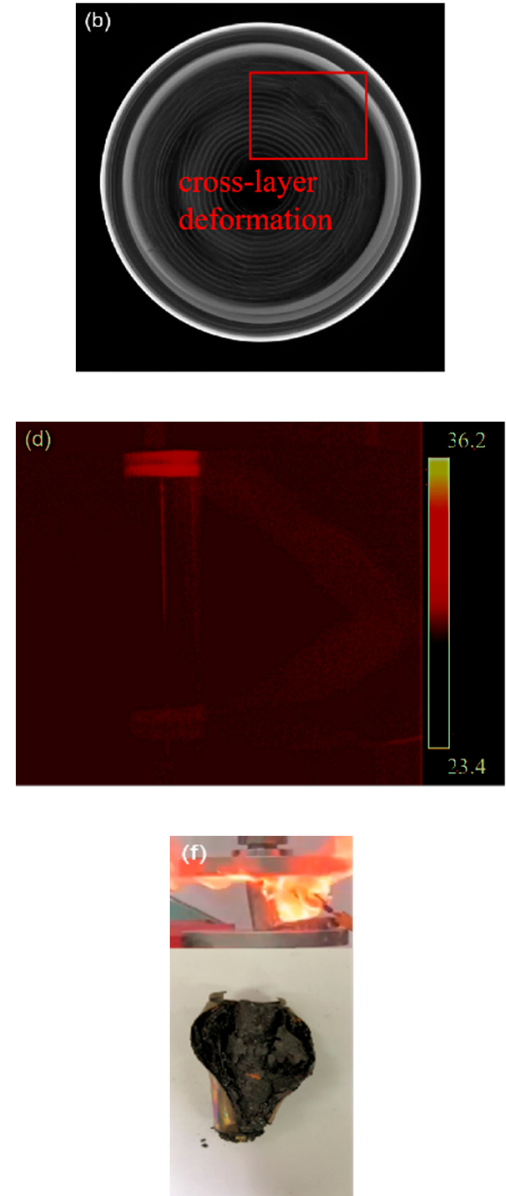

Figure 6. At the end of Stage II: (a) CT inspections of side view; (b) CT scan cross-section close to the positive cap;
(c) temperature nephogram of the battery with $0 \%$ SOC; (d) temperature nephogram of the battery with $40 \%$ SOC;

(e) temperature nephogram of the battery with $80 \%$ SOC; (f) flame in $80 \%$ SOC battery during test and the aftermath.

Figure 7 shows the deformation and temperature of the battery loaded at the end of Stage III. In Figure 7a, the jellyroll was further compressed, resulting in deformation at both the top and bottom parts of the battery. The cross-layer deformation of the jellyroll near the top of the battery is shown in Figure $7 \mathrm{~b}$. The increased contact area between the positive and negative poles led to the electric failure of the battery. At this stage, voltage drops occurred in batteries with $40 \%$ and $60 \%$ SOCs, respectively. As shown in Figure $7 \mathrm{c}$, the jellyroll near the negative pole remained almost intact, with deformation largely limited to the casing of the battery.

Temperature was seen higher near the positive cap of the $0 \%$ SOC battery (Figure 7d) than that at the end of Stage II (Figure 6c). As shown in Figure 7e, the flame bursts near the positive cap of the battery with $60 \% \mathrm{SOC}$, and temperature rises abruptly.

Further tests were carried out with a higher loading rate at $8 \mathrm{~mm} / \mathrm{min}$ on batteries with $40 \%$ and $60 \%$ SOCs. A comparison of test outcomes is given in Figure 8 and Table 1 . 

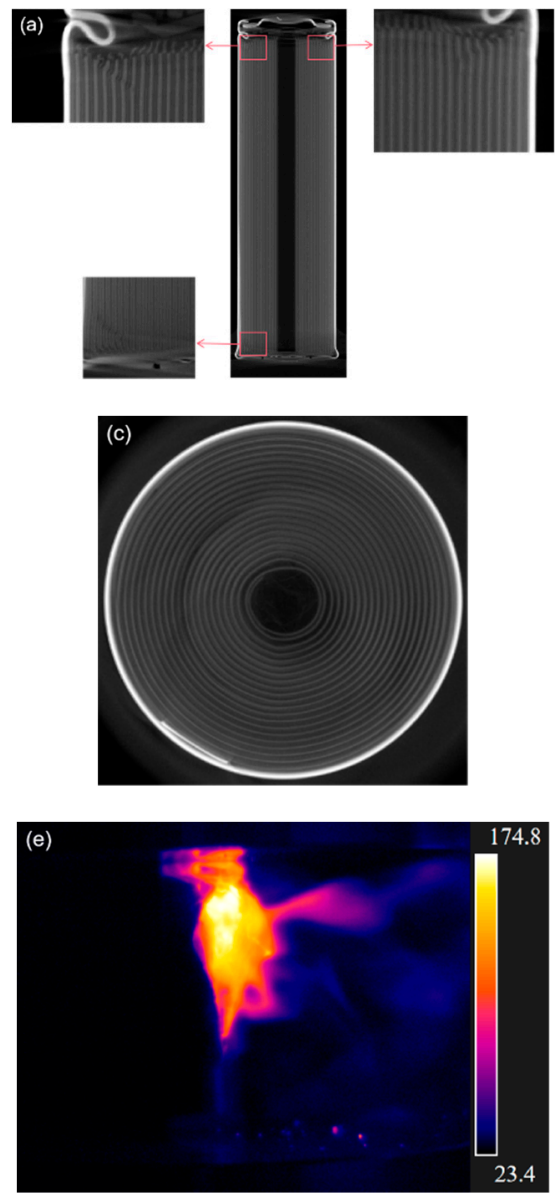
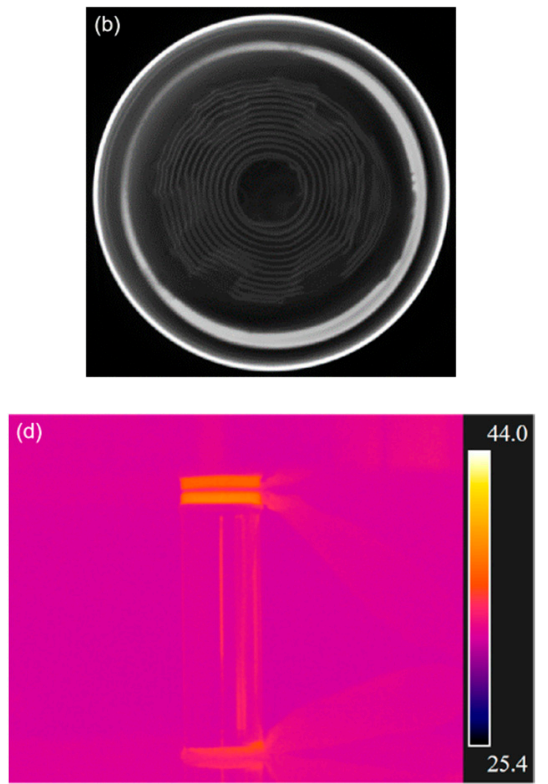

Figure 7. At the end of Stage III: (a) CT scan of side view at the end of Stage III; (b) CT scan of the cross-section near the positive cap; (c) CT scan of the cross-section near the negative pole; (d) temperature nephogram of the battery with $0 \%$ SOC; (e) temperature nephogram of the battery with $40 \%$ SOC.
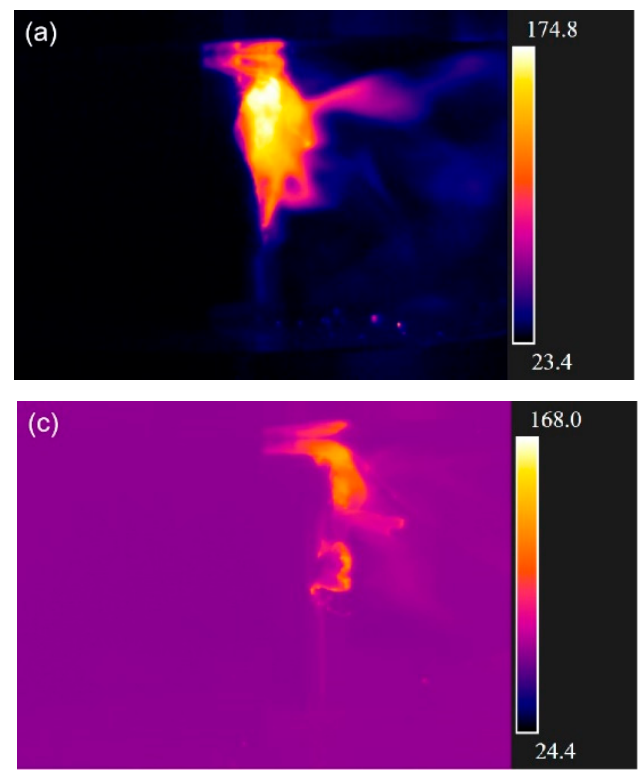
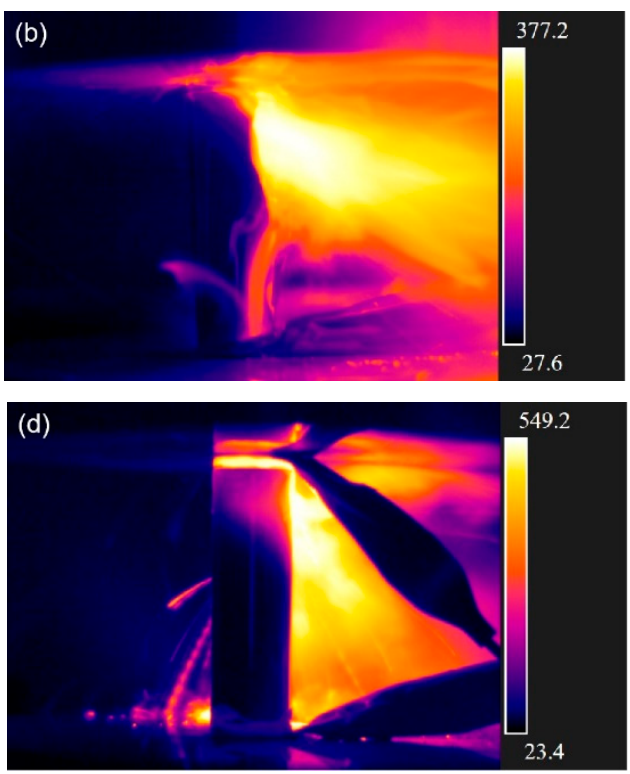

Figure 8. Temperature nephogram under thermal runaway: (a) battery with $40 \%$ SOC at $2 \mathrm{~mm} / \mathrm{min}$; (b) battery with $40 \%$ SOC at $8 \mathrm{~mm} / \mathrm{min}$; (c) battery with $60 \%$ SOC at $2 \mathrm{~mm} / \mathrm{min}$; (d) battery with $60 \%$ SOC at $8 \mathrm{~mm} / \mathrm{min}$. 
Table 1. Experimental results at different loading speeds.

\begin{tabular}{ccccc}
\hline SOC & $\begin{array}{c}\text { Loading Rate } \\
(\mathbf{m m} / \mathbf{m i n})\end{array}$ & $\begin{array}{c}\text { Thermal } \\
\text { Runaway }\end{array}$ & Fire & $\begin{array}{c}\text { Peak Temperature } \\
\left({ }^{\circ} \mathbf{C}\right)\end{array}$ \\
\hline $40 \%$ & 2 & Yes & No & 242 \\
$40 \%$ & 2 & Yes & No & 174 \\
$40 \%$ & 2 & Yes & No & 190 \\
$40 \%$ & 8 & Yes & No & 330 \\
$40 \%$ & 8 & Yes & No & 443 \\
$40 \%$ & 8 & Yes & No & 301 \\
$60 \%$ & 2 & Yes & No & 182 \\
$60 \%$ & 2 & Yes & No & 168 \\
$60 \%$ & 2 & Yes & No & - \\
$60 \%$ & 8 & Yes & Yes & 549 \\
$60 \%$ & 8 & Yes & Yes & 649 \\
$60 \%$ & 8 & Yes & Yes & 672 \\
\hline
\end{tabular}

As shown in Figure 8, the intensity of thermal runaway is more serious under the speed of $8 \mathrm{~mm} / \mathrm{min}$. It can be seen that thermal runaway occurred at a higher temperature in batteries with $40 \% \mathrm{SOC}$, and it occurred to a larger extent but with no flame. The battery with $60 \%$ SOC did not catch fire at the loading rate of $2 \mathrm{~mm} / \mathrm{min}$, but when the loading rate was $8 \mathrm{~mm} / \mathrm{min}$, it burned and burst into flames. Table 1 shows that the peak temperature increases significantly under the loading speed of $8 \mathrm{~mm} / \mathrm{min}$. It is noticed that batteries with $60 \%$ SOC burst into flames under $8 \mathrm{~mm} / \mathrm{min}$, but not $2 \mathrm{~mm} / \mathrm{min}$. This is because the increase in the short-circuit area is slower in the latter, resulting in a slower accumulation of Joule heat. It can be concluded that the intensity of thermal runaway increases with the increase in the loading speed.

\subsection{Axial Impact Experiment (SHPB)}

Compared with the quasi-static axial compression tests, a $19 \mathrm{~mm}$ diameter SHPB device was used to investigate the dynamic response of the batteries. Three striking velocities were selected for the bullet at $9.1 \mathrm{~m} / \mathrm{s}, 11.6 \mathrm{~m} / \mathrm{s}$, and $13.1 \mathrm{~m} / \mathrm{s}$. Lithium-ion batteries with $20 \%, 40 \%, 60 \%$, and $80 \%$ SOCs were tested to explore the mechanical response and failure modes.

Pulse signals in the pressure bar were recorded by a strain gauge on the surface of the incident bar, which was used to calculate the dynamic force impacted on the battery using the following formula:

$$
F=E A\left(\varepsilon_{i}+\varepsilon_{r}\right)
$$

where $\varepsilon_{i}$ and $\varepsilon_{r}$ are the incident and reflected strains, respectively. $E$ is the elastic modulus of the pressure bar, and $A$ is the cross-sectional area of the pressure bar. Again, tests were repeated three or more times to obtain mean values and error estimates on the outcome.

Figure 9a shows the mean peak impact loads of batteries with $20 \%, 40 \%, 60 \%$, and $80 \%$ SOCs at different striking velocities. The measured loads are seen to have little correlation with the SOC, but both the load and the deformation increase clearly with the impact velocity. Figure $9 \mathrm{~b}$ shows the mean values and error bars of the residual deformation of the recovered batteries with $40 \%$ SOC with respect to the impact velocity. The mean residual deformation is seen to increase approximately linearly with the velocity.

Figure 10 shows the CT scans of a tested lithium-ion battery impacted at $11.6 \mathrm{~m} / \mathrm{s}$. It can be seen that deformation occurred at both the positive and negative ends of the battery (Figure 10a,c). The main part of the battery in the middle did not show signs of deformation (Figure 10b). The CT scans show that the jellyroll near the positive cap had deformation, but there was less cross-layer deformation than that in quasi-static tests (Figure $7 b, c)$. The central region of the jellyroll at the negative end was also wrinkled with cross-layer deformation. This may yield internal short circuiting of the battery. There was no severe thermal runaway, and no obvious temperature rise was observed in the dynamic 
tests, which is rather different from the outcome of the quasi-static tests, even though the overall deformation is comparable in the two loading scenarios.
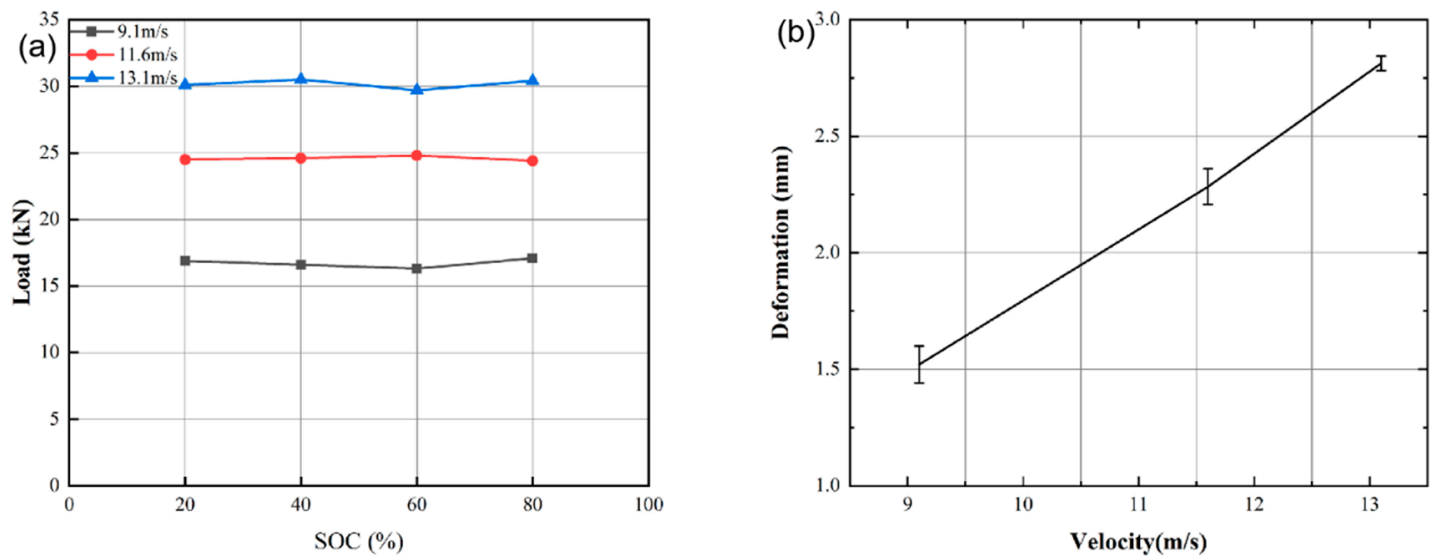

Figure 9. (a) Mean peak impact force on batteries with different SOCs at three striking velocities; (b) mean residual deformation with error bar of batteries with $40 \%$ SOC vs. impact velocity.
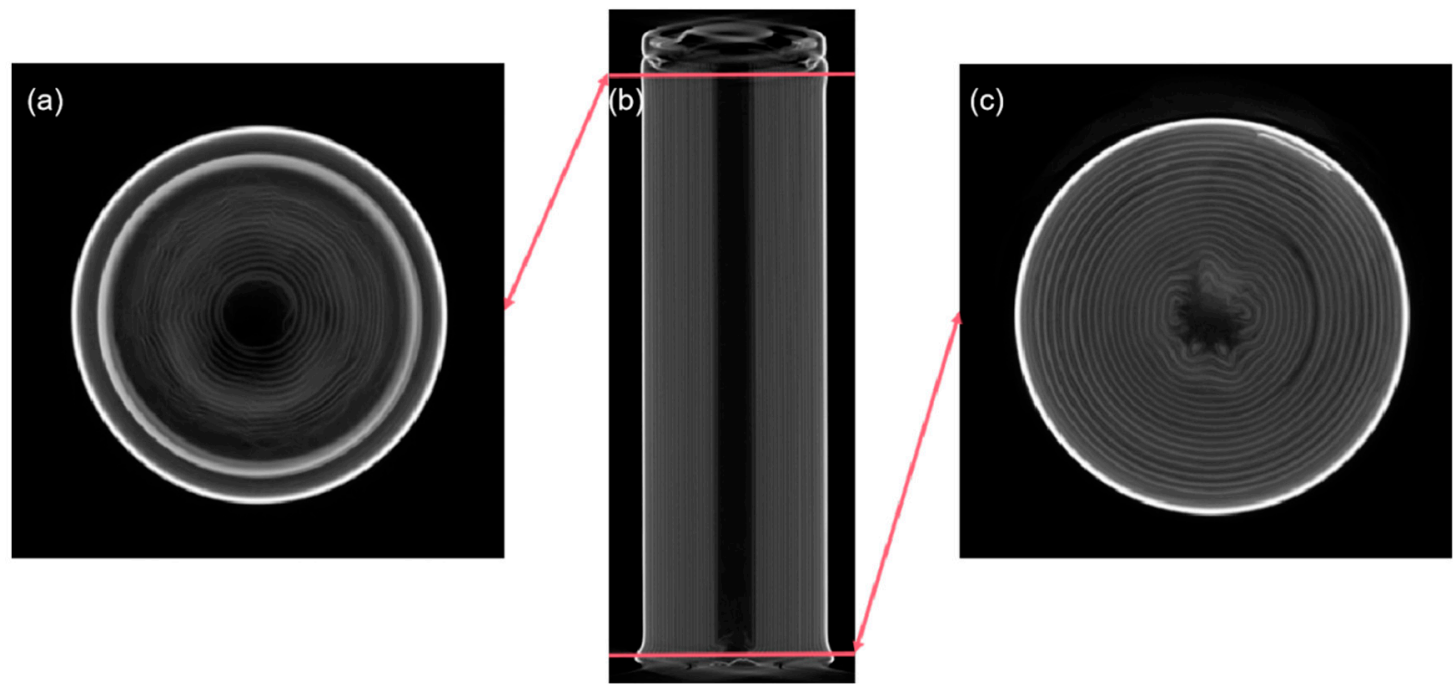

Figure 10. CT inspections after axial impact under $11.6 \mathrm{~m} / \mathrm{s}$ impact: (a) cross-section of the top section; (b) side view; (c) cross-section of the bottom section.

\subsection{Comparison between Dynamic and Quasi-Static Loading}

Based on the experimental outcome, different loading mechanisms can affect the failure forms of batteries. The response of batteries under dynamic and quasi-static loading differs in the following aspects:

(a) Under quasi-static load, the deformation of the battery is mainly concentrated in the positive cap area of the battery with cross-layer deformation in the jellyroll, and little deformation exists at the negative end. Under dynamic impact load, deformation occurs at both the positive and negative electrode ends, but the jellyroll near the positive cap suffers much less cross-layer deformation, and the central region of the jellyroll at the bottom end is wrinkled.

(b) Under quasi-static load, the carrying capacity of the battery is in the range of 6-8 $\mathrm{kN}$, which varies slightly with the SOC. In contrast, the peak transient load capacity of the battery exceeds $15 \mathrm{kN}$ under dynamic impact load.

(c) The failure modes of the battery under the static and dynamic loading are different, even with similar levels of deformation. Thermal runaway occurs under quasi-static loading 
and is related to the level of SOC and the loading velocity. Under dynamic loading, however, only minor internal short circuiting occurs with no thermal runaway.

\section{Discussion}

Under excessive mechanical loading, the occurrence of thermal runaway should be attributed to the various side reactions. Specifically, when abnormal heat builds up inside the battery, a chain of chemical reactions takes place. At first, mechanical abuse causes internal structural damage and internal short circuits, which raise the temperature. When the temperature is beyond $90^{\circ} \mathrm{C}$, lithium salt and SEI film start to decompose. The side reactions caused by abnormal heat accumulation continue to release more heat and form a heat-temperature cycle leading to a fire burst $[27,28]$.

The experimental results show that, under quasi-static axial compression load, the voltage of the battery drops slightly at first in the axial compression process until a complete sudden short-circuit. When the voltage drops for the first time, the temperature at the positive and negative electrode sides begins to rise slightly. Meanwhile, an internal short circuit occurs at the positive and negative poles of the battery. When the battery voltage drops completely, the temperature of the battery rises sharply.

For quasi-static loading, the intensity of battery thermal runaway is different with respect to the level of SOCs. This is because the short-circuit current in the damaged area increases with the battery's SOC, resulting in an increase in Joule heat. Therefore, batteries with excessively high SOCs will experience severe thermal runaway, such as batteries with $80 \%$ SOC. When the electric capacity is lower at, for instance, $40 \%$ or $60 \%$ SOCs, at early loading stages, only smaller areas of the battery are damaged, and the short-circuit current is not big enough to generate sufficient Joule heat to reach the temperature that causes thermal runaway. However, when the battery is further deformed with bigger damaged areas, more Joule heat is generated, which causes thermal runaway.

The intensity of thermal runaway increases with the loading speed. The faster the loading speed, the larger the short-circuit area per unit time, the more Joule heat accumulated, and the more likely it is to have thermal runaway, as shown by the experimental outcome of batteries with $60 \%$ SOC.

In comparison, the experimental results show that under dynamic loading, battery failure modes can be quite different from those under quasi-static loading. Under dynamic impact, the internal damage area of the battery is smaller, resulting in less Joule heat generated by internal short circuits, thus no thermal runaway.

Compared with LiCoO2 [9] and ordinary NCM [29] batteries, it is found that the failure displacement of high-nickel batteries is smaller when axially loaded and easier to burst into flames. The safety of high-nickel batteries still needs to be further improved.

\section{Conclusions}

In this paper, both quasi-static and dynamic axial compression tests were carried out on Hi-Ni lithium-ion batteries with different SOCs. Battery voltages, loading forces, and temperatures in quasi-static axial compression were recorded, and battery failures and thermal runaway intensities were analyzed. In SHPB impact tests, residual deformation and peak loads were recorded. The failure modes of batteries under the two loading forms were compared. The results show that the effect of mechanical loads on the safety performance of cylindrical 18,650 lithium-ion cells depends significantly on the loading form (i.e., either quasi-static loads or dynamic impact). Under quasi-static axial compression, severe thermal runaway occurs in batteries with high SOCs, but not under dynamic impact load for comparable overall deformations. In addition, under quasi-static axial compression, the intensity of thermal runaway becomes more severe with the increase in SOC and loading speed.

The results shed light on the failure mechanism of lithium-ion batteries under axial load and guide the safety design of the battery and safety arrangement of battery packs. 
Author Contributions: Conceptualization, G.W., S.Z., M.L., J.W., B.W. and H.S.; methodology, G.W.; software, S.Z.; resources, G.W.; data curation, S.Z., M.L., J.W.; writing—original draft preparation, S.Z.; writing-review and editing, G.W. and B.W.; funding acquisition, G.W. All authors have read and agreed to the published version of the manuscript.

Funding: This research was funded by the National Natural Science Foundation of China (Grant Number: 11872265) and the Natural Science Foundation of Shanxi Province (Grant Number: 201901D111087).

Institutional Review Board Statement: Not applicable.

Informed Consent Statement: Not applicable.

Data Availability Statement: Not applicable.

Conflicts of Interest: The authors declare no conflict of interest.

\section{Nomenclature}

BMS Battery management system

BTMS Battery thermal management system

CC Constant current

CT Computerized tomography

$\mathrm{CV} \quad$ Constant voltage

EV Electric vehicle

ICE Internal combustion engine

LIB Lithium-ion battery

NCA Lithium nickel-cobalt-alumina oxide

NCM Lithium nickel-cobalt-manganese oxide

SHPB Split Hopkinson pressure bar

SOC State of charge

$\mathrm{SOH}$ State of health

\section{References}

1. Zhu, J.; Wierzbicki, T.; Li, W. A review of safety-focused mechanical modeling of commercial lithium-ion batteries. J. Power Sources 2018, 378, 153-168. [CrossRef]

2. Kaliaperumal, M.; Dharanendrakumar, M.S.; Prasanna, S.; Abhishek, K.V.; Chidambaram, R.K.; Adams, S.; Zaghib, K.; Reddy, M.V. Cause and Mitigation of Lithium-Ion Battery Failure-A Review. Materials 2021, 14, 5676. [CrossRef]

3. Dubaniewicz, T.H.; DuCarme, J.P. Are Lithium-Ion Cells Intrinsically Safe? IEEE Trans. Ind. Appl. 2013, 49, 2451-2460. [CrossRef]

4. Li, Y.; Yang, J.; Song, J. Design principles and energy system scale analysis technologies of new lithium-ion and aluminum-ion batteries for sustainable energy electric vehicles. Renew. Sustain. Energy Rev. 2017, 71, 645-651. [CrossRef]

5. Li, L.; Ju, X.; Zhou, X.; Peng, Y.; Zhou, Z.; Cao, B.; Yang, L. Experimental Study on Thermal Runaway Process of 18650 Lithium-Ion Battery under Different Discharge Currents. Materials 2021, 14, 4740. [CrossRef] [PubMed]

6. Lee, W.; Muhammad, S.; Sergey, C.; Lee, H.; Yoon, J.; Kang, Y.; Yoon, W. Advances in the Cathode Materials for Lithium Rechargeable Batteries. Angew. Chem. Int. Ed. 2020, 59, 2578-2605. [CrossRef]

7. Zhu, J.; Zhang, X.; Wierzbicki, T.; Xia, Y.; Chen, G. Structural Designs for Electric Vehicle Battery Pack against Ground Impact; 2018-01-1438; SAE Technical Paper; SAE International WCX World Congress Experience: Detroit, MI, USA, 2018.

8. Xia, Y.; Wierzbicki, T.; Sahraei, E.; Zhang, X. Damage of cells and battery packs due to ground impact. J. Power Sources 2014, 267, 78-97. [CrossRef]

9. Zhu, J.; Zhang, X.; Sahraei, E.; Wierzbicki, T. Deformation and failure mechanisms of 18650 battery cells under axial compression. J. Power Sources 2016, 336, 332-340. [CrossRef]

10. Xu, J.; Liu, B.; Hu, D. State of Charge Dependent Mechanical Integrity Behavior of 18650 Lithium-ion Batteries. Sci. Rep. 2016, 6, 21829. [CrossRef] [PubMed]

11. Xu, J.; Liu, B.; Wang, X.; Hu, D. Computational model of 18650 lithium-ion battery with coupled strain rate and SOC dependencies. Appl. Energy 2016, 172, 180-189. [CrossRef]

12. Xu, J.; Jia, Y.; Liu, B.; Zhao, H.; Yu, H.; Li, J.; Yin, S. Coupling Effect of State-of-Health and State-of-Charge on the Mechanical Integrity of Lithium-Ion Batteries. Exp. Mech. 2018, 58, 633-643. [CrossRef]

13. Avdeev, I.; Gilaki, M. Structural analysis and experimental characterization of cylindrical lithium-ion battery cells subject to lateral impact. J. Power Sources 2014, 271, 382-391. [CrossRef]

14. Xu, J.; Liu, B.; Wang, L.; Shang, S. Dynamic mechanical integrity of cylindrical lithium-ion battery cell upon crushing. Eng. Fail. Anal. 2015, 53, 97-110. [CrossRef] 
15. Sahraei, E.; Hill, R.; Wierzbicki, T. Calibration and finite element simulation of pouch lithium-ion batteries for mechanical integrity. J. Power Sources 2012, 201, 307-321. [CrossRef]

16. Greve, L.; Fehrenbach, C. Mechanical testing and macro-mechanical finite element simulation of the deformation, fracture, and short circuit initiation of cylindrical Lithium-ion battery cells. J. Power Sources 2012, 214, 377-385. [CrossRef]

17. Dixon, B.; Mason, A.; Sahraei, E. Effects of electrolyte, loading rate and location of indentation on mechanical integrity of li-ion pouch cells. J. Power Sources 2018, 396, 412-420. [CrossRef]

18. Hao, W.; Yuan, Z.; Xu, Y.; Zhu, S.; Chen, H.; Fang, D. Damage analysis of cylindrical lithium-ion cells under three-points bending using acoustic emission. J. Power Sources 2019, 444, 227323. [CrossRef]

19. Gao, Z.; Zhang, X.; Xiao, Y.; Wang, H.; Li, N. Influence of coupling of overcharge state and short-term cycle on the mechanical integrity behavior of $18650 \mathrm{Li}$-ion batteries subject to lateral compression. Int. J. Hydrog. Energy 2018, 43, 5261-5271. [CrossRef]

20. Gao, Z.; Zhang, X.; Xiao, Y.; Gao, H.; Wang, H.; Piao, C. Influence of Low-Temperature Charge on the Mechanical Integrity Behavior of 18650 Lithium-Ion Battery Cells Subject to Lateral Compression. Energies 2019, 12, 797. [CrossRef]

21. Panchal, S.; Rashid, M.; Long, F.; Mathew, M.; Fraser, R.; Fowler, M. Degradation Testing and Modeling of $200 \mathrm{Ah} \mathrm{LiFePO}_{4}$ Battery for EV; 2018-01-0441; SAE Technical Paper; SAE International WCX World Congress Experience: Detroit, MI, USA, 2018.

22. Panchal, S.; Mathewson, S.; Fraser, R.; Culham, R.; Fowler, M. Experimental Measurements of Thermal Characteristics of LiFePO 4 Battery; 2015-01-1189; SAE Technical Paper; SAE 2015 World Congress \& Exhibition: Detroit, MI, USA, 2015.

23. Duan, J.; Zhao, J.; Li, X.; Panchal, S.; Yuan, J.; Fraser, R.; Fowler, M. Modeling and Analysis of Heat Dissipation for Liquid Cooling Lithium-Ion Batteries. Energies 2021, 14, 4187. [CrossRef]

24. Kisters, T.; Sahraei, E.; Wierzbicki, T. Dynamic impact tests on lithium-ion cells. Int. J. Impact Eng. 2017, 108, 205-216. [CrossRef]

25. Wang, D.; Zheng, L.; Li, X.; Du, G.; Feng, Y.; Jia, L.; Dai, Z. Effect of high Ni on battery thermal safety. Int. J. Energy Res. 2020, 44, 12158-12168. [CrossRef]

26. Liu, H.; Naqvi, I.; Li, F.; Liu, C.; Shafiei, N.; Li, Y.; Pechtb, M. An analytical model for the CC-CV charge of Li-ion batteries with application to degradation analysis. J. Energy Storage 2020, 29, 101342. [CrossRef]

27. Song, L.; Zheng, Y.; Xiao, Z.; Wang, C.; Long, T. Review on Thermal Runaway of Lithium-Ion Batteries for Electric Vehicles. J. Electron. Mater. 2022. [CrossRef]

28. Liu, X.; Ren, D.; Hsu, H.; Feng, X.; Xu, G.; Zhuang, M.; Gao, H.; Lu, L.; Han, X.; Chu, Z.; et al. Thermal Runaway of Lithium-Ion Batteries without Internal Short Circuit. Joule 2018, 2, 2047-2064. [CrossRef]

29. Li, M.; Liu, X.; Zhang, S.; Song, H.; Wang, G.; Wang, B. Performance of Cylindrical Power Lithium-Ion Battery under Axial Compression. Chin. J. High Press. Phys. 2021, 35, 035302. 